\section{УДК 636.085.55:664}

06.02.10 Частная зоотехния, технология производства продуктов животноводства

\section{ОПТИМИЗАЦИЯ СООТНОШЕНИЯ БИОЛОГИЧЕСКИ АКТИВНЫХ ВЕЩЕСТВ И ПРОБИОТИЧЕСКОЙ МИКРОФЛОРЫ В РЕЦЕПТЕ КОМПЛЕКСНОГО КОРМОВОГО КОНЦЕНТРАТА}

Казарян Роберт Врамович

д.т.н., профессор, г.н.с.

РИНЦ SPIN-код: 7893-0259, AuthorID: 662717

Бородихин Александр Сергеевич

H.c.

РИНЦ SPIN-код: 6146-7484, AuthorID: 606879

Лукьяненко Мария Викторовна

к.T.H., с.н.c.

РИНЦ SPIN-код: 5215-4078

Краснодарский научно-исследовательский инсти тут хранения и переработки сельскохозяйственной продукции - филиал ФГБНУ «Северо-

Кавказский федеральный научный иентр садоводства, виноградарства, виноделия», Россия, 350072, 2. Краснодар, ул. Тополиная аллея, д.2

kisp@kubannet.ru

Семененко Марина Петровна

д.в.н., зав. отделом

SPIN-код: 2038-7259, AuthorID: 178663

Мирошниченко Петр Васильевич

к.В.H., с.н.с.

РИНЦ SPIN-код: 5399-6586, AuthorID: 728643

Кузьминова Елена Васильевна

д.в.н., в.н.с.

SPIN-код: 1897-5113, AuthorID: 359696

Краснодарский научныии иентр по зоотехнии и ветеринарии, Россия, 350055, Краснодарский край, г. Краснодар, пос. Знаменский, уп.Первомайская, д. .

Обеспечение населения основными продуктами питания - источниками белков, жиров, углеводов, витаминов и других важнейших нутриентов является одним из главных вопросов обеспечения безопасности страны, при этом требование соблюдения безопасности продуктов питания - главенствующее. Наибольшее значение в условиях интенсификации сельского хозяйства и повышения конкурентоспособности животноводческих хозяйств приобретает производство кормовых добавок (концентратов), улучшающих конверсию корма, при этом являющихся натуральными и безопасными для здоровья животных. В качестве одного из эффективных методов борьбы с нежелательной микрофлорой в пищеварительном тракте
UDC $636.085 .55 \cdot 664$

06.02.07 Private animal husbandry, technology of production of livestock products

\section{OPTIMIZATION OF THE RELATION OF BIOLOGICALLY ACTIVE SUBSTANCES AND PROBIOTIC MICROFLORA IN THE RECIPE OF COMPLEX FEED CONCENTRATE}

Kazaryan Robert Vramovich

Dr.Sci.Tech, professor, chief researcher

RISC SPIN-code: 7893-0259, AuthorID: 662717

Borodihin Alexander Sergeevich

researcher

RISC SPIN-code: 6146-7484, AuthorID: 606879

Lukyanenko Maria Viktorovna

Cand.Tech.Sci., senior researcher, RSCI SPIN-code:

5215-4078

Krasnodar Scientific Research Institute of Storage and Processing of Agricultural Products - branch of the FSBSI «North-Caucasian Federal Scientific Center for Horticulture, Viticulture and Wine-Making», Russia, 350072, Krasnodar, st.Topolinaya alleya, 2

kisp@kubannet.ru

Semenenko Marina Petrovna

Dr.Sci.Vet., head of Department

RISC SPIN-code: 2038-7259, AuthorID: 178663

Miroshnichenko Peter Vasilyevich

Cand.Vet.Sci., senior researcher

RISC SPIN-code: 5399-6586, AuthorID: 728643

Kuzminova Elena Vasilyevna

Dr.Sci.Vet., leading Researcher

RISC SPIN-code: 1897-5113, AuthorID: 359696

Krasnodar Research Center for Animal Husbandry and Veterinary Medicine, Russia, Krasnodar region, Krasnodar, pos. Znamensky, Pervomayskaya, 4

Providing the population with basic foodstuffs, sources of proteins, fats, carbohydrates, vitamins and other essential nutrients is one of the main issues of ensuring the security of the country, while the requirement for food safety is paramount. Production of feed additives (concentrates), which improve feed conversion, while being natural and safe for animal health, acquires the greatest importance in the conditions of intensification of agriculture and increasing the competitiveness of livestock farms. Probiotic microflora, which, in competition with pathogenic, displaces the latter from the gastrointestinal tract, can be considered as one of the effective methods of controlling undesirable microflora in the digestive tract. In world science, research is actively conducted in the direction of searching for 
может рассматриваться пробиотическая микрофлора, которая в конкуренции с патогенной вытесняет последнюю из желудочно-кишечного тракта. В мировой науке активно ведутся исследования в направлении поиска эффективных пробиотических культур. Перспективным направлением повышения эффективности применения пробиотических кормовых добавок является их дополнение пребиотиками, например, включающими в свой состав витамины (антиокислители) и минеральные вещества (селен). Целью настоящей работы являлось определение оптимального соотношения биологически активных веществ, содержащихся в кормовом витаминно-минеральном концентрате, и пробиотической микрофлоры, содержащейся в кормовой пробиотической добавке Бацелл-М, для разработки комплексного кормового концентрата. С применением функции желательности Харрингтона определено (выявлено) оптимальное соотношение биологически активных веществ и пробиотической микрофлоры в рецепте комплексного кормового концентрата, обеспечивающее максимальное снижение содержания аланинаминотрансферазы в сыворотке крови опытных животных, характеризующее нормализацию барьерных органов

Ключевые слова: ЛАБОРАТОРНЫЕ ЖИВОТНЫЕ, ПРОБИОТИК, БИОЛОГИЧЕСКИ АКТИВНЫЕ ВЕЩЕСТВА, ОПТИМИЗАЦИЯ, КОМПЛЕКСНЫЙ КОРМОВОЙ КОНЦЕНТРАТ

Doi: 10.21515/1990-4665-148-032 effective probiotic cultures. A promising way to increase the effectiveness of the use of probiotic feed additives is their addition to prebiotics, for example, including vitamins (antioxidants) and mineral substances (selenium). The purpose of this work was to determine the optimal ratio of biologically active substances contained in the feed vitamin-mineral concentrate, and probiotic microflora contained in the feed probiotic additive Bacell-M, for the development of complex feed concentrate. Using the Harrington's desirability function, the optimum ratio of biologically active substances and probiotic microflora in the recipe of the complex feed concentrate is determined, ensuring the maximum reduction in the serum levels of alanine aminotransferase in the blood serum of experimental animals, which characterizes the normalization of barrier organs.

Keywords: LABORATORY ANIMALS, PROBIOTIC, BIOLOGICALLY ACTIVE SUBSTANCES, OPTIMIZATION, COMPLEX FEED

Обеспечение населения основными продуктами питания, источниками белков, жиров, углеводов, витаминов и других важнейших нутриентов является одним из главных вопросов обеспечения безопасности страны, при этом требование соблюдения безопасности продуктов питания главенствующее.

Специалисты за рубежом, решая проблему наращивания продуктивности в животноводстве, отдают предпочтение использованию стимуляторов и антибиотиков. Если продукция предназначена для реализации в России, никто не озабочен вопросом, как долго эти вещества удерживаются в организме, где и в каких количествах депонируются [1].

Наибольшее значение в условиях интенсификации сельского хозяйства и повышения конкурентоспособности животноводческих хозяйств приобретает производство кормовых добавок (концентратов), улучшаю- 
щих конверсию корма, при этом являющихся натуральными и безопасными для здоровья животных [2,3].

Необходимо учитывать, что при выращивании сельскохозяйственных животных и птицы существует такой негативный фактор, как спонтанная микрофлора в пищеварительном тракте, которая в процессе своей жизнедеятельности выделяет собственные метаболиты, приводящие к нарушению обменных процессов, возникновению заболеваний органов пищеварительной системы и, в конечном итоге, к ухудшению здоровья и снижению продуктивности, независимо от затрат на введение в рацион кормовых добавок.

В качестве одного из эффективных методов борьбы с нежелательной микрофлорой в пищеварительном тракте может рассматриваться пробиотическая микрофлора, которая в конкуренции с патогенной вытесняет последнюю из желудочно-кишечного тракта. В мировой науке активно ведутся исследования в направлении поиска эффективных пробиотических культур.

Перспективным направлением повышения эффективности применения пробиотических кормовых добавок является их дополнение пребиотиками, например, включающими в свой состав витамины (антиокислители) и минеральные вещества (селен).

Учитывая это, целью настоящей работы являлось определение оптимального соотношения биологически активных веществ и пробиотической микрофлоры в комплексном кормовом концентрате.

При выборе объектов исследования предпочтение было отдано ранее разработанным и опробованным в животноводстве комплексам биологически активных веществ и пробиотической микрофлоры. Авторами, в качестве комплекса биологически активных веществ, был выбран концентрат витаминно-минеральный кормовой (КВМК). Для внесения в рецепт 
комплекса пробиотической микрофлоры использовалась хорошо себя зарекомендовавшая, кормовая пробиотическая добавка Бацелл-М.

Для проведения опытов in vivo было отобрано 80 здоровых лабораторных животных одного возраста, массы, физиологического состояния и обоего пола.

На основе предыдущих исследований при планировании эксперимента для уточнения численных параметров функции оптимизации были приняты следующие предположения: поверхность отклика - гладкая, непрерывная функция, функция имеет единственный экстремум. Изменяемые факторы: содержание комплекса биологически активных веществ КВМК $(y)$ и добавки кормовой пробиотической Бацелл-М $(x)$. Единицами измерения факторов выбрано их отношение к основному рациону, выраженное в процентах.

При планировании эксперимента были выбраны кодированные значения неполнофакторного эксперимента для двух факторов в трёх уровнях и дополнительные точки для нулевых уровней каждого фактора в базовой точке эксперимента, позволяющие наиболее полно определить параметры математической модели [4]. Базовая точка эксперимента была установлена согласно инструкциям по использованию КВМК $(y=0,3)$ и кормовой пробиотической добавки Бацелл-М $(x=0,2)$ [5,6]. В дальнейшем, с учётом полученных экспериментальных данных, в ходе модельно-кибернетического опыта были получены точки, характеризующие зависимость воздействия факторов на лабораторных животных без взаимного влияния.

В качестве функций отклика были выбраны: изменение массы животных, содержание белка в сыворотке крови, уровень активности ферментов аланинаминотрансферазы (АлАТ) и аспартатаминотрансферазы (AcAT), как индикаторов состояния барьерных органов. 
В соответствии с планом эксперимента животных разделили на 8 групп по 10 голов в каждой по принципу пар-аналогов и кормили в соответствии с таблицей планирования эксперимента (таблица).

Таблица - План эксперимента

\begin{tabular}{|c|c|c|c|c|c|}
\hline \multirow[b]{2}{*}{$\begin{array}{l}\text { № } \\
\Pi / \Pi\end{array}$} & \multicolumn{2}{|c|}{ Бацелл-М } & \multicolumn{2}{|r|}{ KMBK } & \multirow[b]{2}{*}{$\begin{array}{c}\text { Описание } \\
\text { точки }\end{array}$} \\
\hline & $\begin{array}{c}\mathrm{x}\left(\mathrm{x}_{1}\right) \text { в } \\
\text { плане }\end{array}$ & $\begin{array}{c}\text { x }\left(\mathrm{x}_{1}\right), \% \text { к ос- } \\
\text { новному рацио- } \\
\text { ну }\end{array}$ & $\begin{array}{c}\mathrm{y}\left(\mathrm{x}_{2}\right) \text { в } \\
\text { плане }\end{array}$ & $\begin{array}{c}\mathrm{y}\left(\mathrm{x}_{2}\right), \% \text { к ос- } \\
\text { новному рацио- } \\
\text { ну }\end{array}$ & \\
\hline 1 & 0 & 0,2 & $*$ & 0 & контроль \\
\hline 2 & $*$ & 0 & 0 & 0,3 & контроль \\
\hline 3 & 0 & 0,2 & 0 & 0,3 & опыт \\
\hline 4 & -1 & 0,1 & -1 & 0,2 & опыт \\
\hline 5 & +1 & 0,3 & +1 & 0,4 & опыт \\
\hline 6 & +1 & 0,3 & 0 & 0,3 & опыт \\
\hline 7 & 0 & 0,2 & +1 & 0,4 & опыт \\
\hline 8 & $*$ & 0 & $*$ & 0 & контроль \\
\hline$*$ & $*$ & 0 & +1 & 0,4 & модель \\
\hline$*$ & +1 & 0,3 & $*$ & 0 & модель \\
\hline
\end{tabular}

* фактор не участвует в варианте; модель - прогноз на основе ранее полученных данных, точка не участвует в опыте на лабораторных животных; контроль - краевые опытные точки для уточнения математической модели; опыт - основные точки плана эксперимента.

Далее был проведён регрессионный анализ экспериментальных данных и получены поверхности отклика для показателей состава крови и массы животных.

Поиск оптимума рецепта проведен с помощью обобщенного параметра оптимизации по методике «функции желательности» Харрингтона [7]. Критериями оптимальности выбраны: характеристика, косвенно оценивающая результативность общего воздействия факторов по показателям состояния здоровья и дополнительные расходы при кормлении (стоимость комплексного кормового концентрата).

После корреляционного анализа, для исключения применения взаимозависимых величин, в качестве индикатора здоровья из функций откли- 
ка выбрана активность аланинаминотрансферазы (АлАТ) [8], как обладающей наибольшим градиентом значений (рисунок 1).

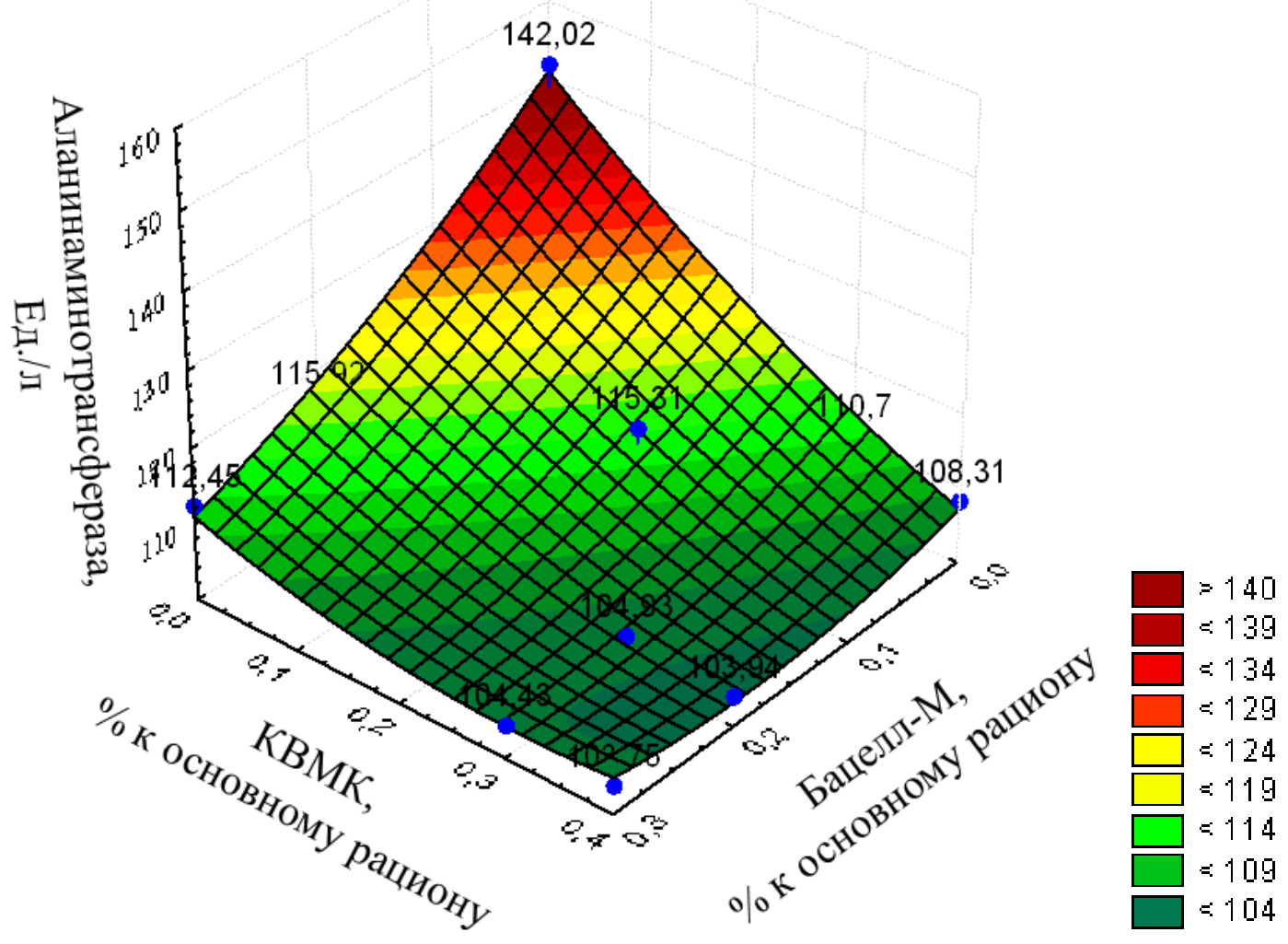

Рисунок 1 - Вид функции активности аланинаминотрансферазы в экспериментальном диапазоне

Сформировав критерий желательности Харрингтона $(\mathrm{z}=\mathrm{f}(x, y))$, для параметров оптимизации были выбраны диапазоны варьирования: $x$ от 0 до 0,3 и у от 0 до 0,4. Численно обработав с помощью STATISTICA, Lazarus и Excel уравнение Харрингтона, графически представленное на рисунке 2, был найден локальный оптимум: $x=0,20 ; y=0,31 ; \mathrm{z}=0,94 ;$ при этом $\mathrm{z}(0.2,0.3)=0,94$.

Различие функции желательности для $y=0,31$ и $y=0,3$ минимально, поэтому в целях оптимизации за базовое значение было принято количество вносимого в корм КМВК $y=0,3 \%$ к массе основного рациона, а за базовое значение - количество вносимого в корм Бацелл-М $x=0,2 \%$ к массе 
основного рациона.

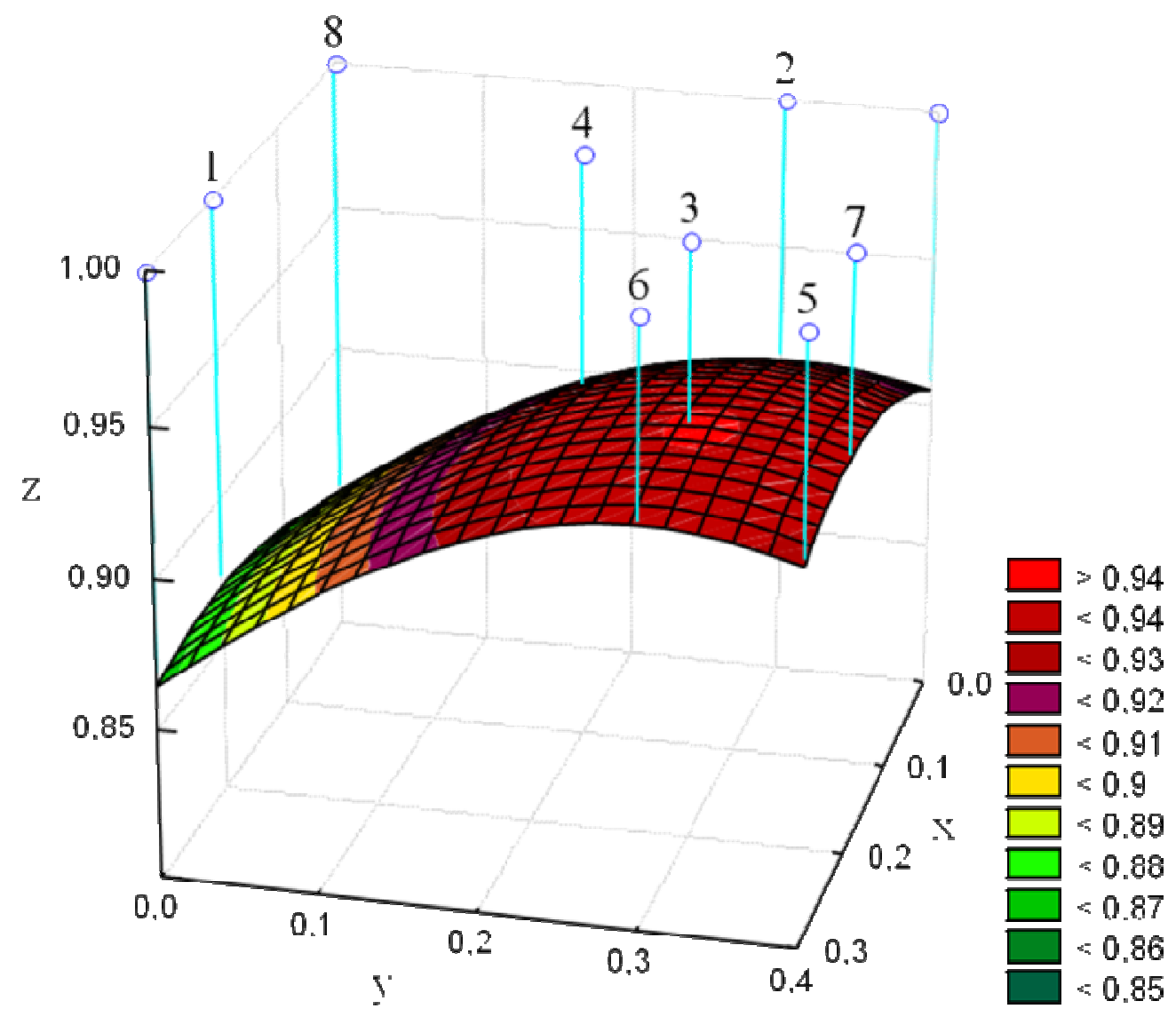

Рисунок 2 - Вид функции желательности Харрингтона

в экспериментальном диапазоне

Таким образом, на основании полученных данных был разработан рецепт комплексного кормового концентрата, включающий замену части носителя концентрата витаминно-минерального кормового на кормовую пробиотическую добавку Бацелл-М, отражающий установленное эффективное соотношение комплекса биологически активных веществ, содержащихся в концентрате витаминно-минеральном кормовом, и пробиотической микрофлоры в составе кормовой пробиотической добавки Бацелл-М.

\section{Литература:}

1. Ганенко, И. Накормим сами [Текст]/ И. Ганенко // Агроинвестор. - 2009. - №4. URL: https:// www.agroinvestor.ru/ markets/article/11040/ (дата обращения: 2018-10-23).

2. Казарян, Р.В. Перспективные направления применения пробиотиков для создания полифункциональных кормовых добавок [Текст]/ Р.В. Казарян, А.С. Бородихин, М.В. Лукьяненко, А.Д. Ачмиз, А.Н. Матвиенко //Новые технологии. - 2018. - №. 2. - С. 116-121. 
3. Богомолов, В.В. Технологические аспекты получения новых кормовых продуктов [Текст]/ В.В. Богомолов// Генетика и разведение животных. - 2016. - № 3. - С. $35-40$.

4. Скоринкин, А.И. Математическое моделирование биологических процессов [Текст]//Учебно-методическое пособие. Казань: Казан. ун-т. - 2015. - 86с.

5. Инструкция по применению добавки кормовой пробиотической Бацелл-М для нормализации процессов пищеварения, повышения продуктивности и сохранности сельскохозяйственных животных, птиц и рыб // OOO «Биотехагро» URL: https://биотехагро.pф/produktsiya-zhivotnovodstvo/bacell-m-instrukciya (дата обращения: 2019-01-20).

6. Казарян Р.В. Влияние полифункдиональной кормовой добавки «Тетра+» на качество, безопасность и эффективность производства мяса кур и яиц [Текст]/ Р.В. Казарян, А.А. Фабрицкая, В.В. Лисовой, А.С. Бородихин, П.В. Мирошниченко //Технологии пищевой и перерабатывающей промышленности АПК-продукты здорового питания. - 2015. - №. 3 (7). - С. 11-16.

7. Методика проектирования рецептур инновационных продуктов с использованием обобщённой функции желательности Харрингтона [Текст]/ Евдокимова О.В., Марков В.В., Курнакова О.Л. // Ползуновский вестник. 2015. № 2. С. 74-78.

8. Маркелова Н.Н., Красноперов А.С., Лебедева И.А. Повышение биоресурсного потенциала кур-несушек в период принудительной линьки с использованием пробиотической кормовой добавки Бацелл-М [Текст] //Птица и птицепродукты. - 2014. №. 5. - C. 65-67.

\section{References}

1. Ganenko, I. Nakormim sami [Tekst]/ I. Ganenko // Agroinvestor. - 2009. - №4. URL: https:// www.agroinvestor.ru/ markets/article/11040/ (data obrashheniya: 2018-10-23).

2.Kazaryan, R.V. Perspektivny`e napravleniya primeneniya probiotikov dlya sozdaniya polifunkcional'ny`x kormovy`x dobavok [Tekst]/ R.V. Kazaryan, A.S. Borodixin, M.V. Luk yanenko, A.D. Achmiz, A.N. Matvienko //Novy`e texnologii. - 2018. - №. 2. - S. 116121.

3. Bogomolov, V.V. Texnologicheskie aspekty` polucheniya novy`x kormovy`x produktov [Tekst]/ V.V. Bogomolov// Genetika i razvedenie zhivotny`x. - 2016. - № 3. - S. 35-40.

4. Skorinkin, A.I. Matematicheskoe modelirovanie biologicheskix processov [Tekst]//Uchebno-metodicheskoe posobie. Kazan`: Kazan. un-t. - 2015. - 86s.

5. Instrukciya po primeneniyu dobavki kormovoj probioticheskoj Bacell-M dlya normalizacii processov pishhevareniya, povy`sheniya produktivnosti i soxrannosti sel`skoxozyajstvenny`x zhivotny`x, pticz i ry`b // OOO «Biotexagro» URL: https://biotexagro.rf/produktsiya-zhivotnovodstvo/bacell-m-instrukciya (data obrashheniya: 2019-01-20).

6. Kazaryan R.V. Vliyanie polifunkdional`noj kormovoj dobavki «Tetra+» na kachestvo, bezopasnost` i e`ffektivnost` proizvodstva myasa kur i yaicz [Tekst]/ R.V. Kazaryan, A.A. Fabriczkaya, V.V. Lisovoj, A.S. Borodixin, P.V. Miroshnichenko //Texnologii pishhevoj i pererabaty`vayushhej promy`shlennosti APK-produkty`zdorovogo pitaniya. 2015. - №. 3 (7). - S. 11-16.

7. Metodika proektirovaniya receptur innovacionny`x produktov $\mathrm{s}$ ispol’zovaniem obobshhyonnoj funkcii zhelatel nosti Xarringtona [Tekst]/ Evdokimova O.V., Markov V.V., Kurnakova O.L. // Polzunovskij vestnik. 2015. № 2. S. 74-78.

8. Markelova N.N., Krasnoperov A.S., Lebedeva I.A. Povy`shenie bioresursnogo potenciala kur-nesushek $\mathrm{v}$ period prinuditel’noj lin`ki $\mathrm{s}$ ispol’zovaniem probioticheskoj kormovoj dobavki Bacell-M [Tekst] //Pticza i pticeprodukty`. - 2014. - №. 5. - S. 65-67. 